Compositio Mathematica 139: 381, 2003.

\title{
Author Index, Volume 139 (2003)
}

Avanzi, R. M. 263

Baklouti, A. 29

Bowman, D. 85

Bradley, D. M. 85

Buium, A. 197

Diaconu, A. 297

Fujiwara, H. 29

Goldfeld, D. 297
Goresky, M. 1

Hain, R. 119

Hoffstein, J. 297

Ion, B. 67

Matsumoto, M. 119

Nollet, S. 169

Roggero, M. 101

Śliwa, W. 113
Schlesinger, E. 169

Tai, Y. S. 1

Tziolas, N. 239

Valabrega, P. 101

Vasconcelos, W. V. 361

Zannier, U. M. 263 